\title{
Ectopic Lymphoid Structures: Powerhouse of Autoimmunity
}

\author{
Elisa Corsiero, Alessandra Nerviani, Michele Bombardieri and Costantino Pitzalis* \\ Centre for Experimental Medicine and Rheumatology, William Harvey Research Institute, Barts and The London School of \\ Medicine and Dentistry, Queen Mary University of London, London, UK
}

Ectopic lymphoid structures (ELS) often develop at sites of inflammation in target tissues of autoimmune diseases, such as rheumatoid arthritis, Sjögren's syndrome, multiple sclerosis, myasthenia gravis, and systemic lupus erythematosus. ELS are characterized by the formation of organized T/B cells aggregates, which can acquire follicular dendritic cells network supporting an ectopic germinal center response. In this review, we shall summarize the mechanisms that regulate the formation of ELS in tertiary lymphoid organs, with particular emphasis on the role of lymphoid chemokines in both formation and maintenance of ELS, the role of emerging positive and negative regulators of ELS development and function, including T follicular helper cells and IL-27, respectively. Finally, we shall discuss the main functions of ELS in supporting the affinity maturation, clonal selection, and differentiation of autoreactive $B$ cells contributing to the maintenance and perpetuation of humoral autoimmunity.

\section{OPEN ACCESS}

Edited by:

Pasquale Maffia

University of Glasgow, UK

Reviewed by:

Silvano Sozzani,

University of Brescia, Italy

Mark Christopher Coles,

University of York, UK

*Correspondence:

Costantino Pitzalis

c.pitzalis@qmul.ac.uk

Specialty section: This article was submitted to Inflammation,

a section of the journal

Frontiers in Immunology

Received: 13 August 2016 Accepted: 30 September 2016 Published: 17 October 2016

Citation:

Corsiero E, Nerviani A Bombardieri M and Pitzalis C (2016) Ectopic Lymphoid Structures: Powerhouse of Autoimmunity.

Front. Immunol. 7:430. doi: 10.3389/fimmu.2016.00430
Keywords: tertiary lymphoid structures, autoimmunity, lymphoid chemokines, autoimmune diseases, ectopic germinal center

\section{INTRODUCTION}

It is now well appreciated that ectopic (or tertiary) lymphoid structures (ELS) can develop in target organs of several autoimmune diseases, which are sites of chronic inflammation, although they can also develop in association with cancer, infection, and graft rejection, as previously discussed (1). At particular mucosal sites, ELS can be named based on the site of inflammation where they occur, e.g., inducible bronchus-associated or gut-associated lymphoid tissue or iGALT and iBALT, respectively (2). ELS are characterized by aggregates of T and B cells often showing T/B segregation (i.e., separated areas within the aggregates densely populated by $\mathrm{T}$ or $\mathrm{B}$ cells only), development of high endothelial venules (HEVs), and, in the majority of cases, follicular dendritic cell (FDC) networks. Compared to lymphoid aggregates forming in secondary lymphoid organs (SLOs), ELS are transient structures that can be triggered by immunization or infection (3) and often resolve after antigen clearance (2). However, in autoimmune diseases, ELS mostly develop in the context of a chronic inflammation, contribute to maintain the disease process, and are often associated with a more severe disease course $(1,4)$. As we shall discuss later in this review, ELS developing in chronic autoimmune conditions are capable of activating the molecular machinery to sustain in situ antibody diversification, isotype switching, B cell differentiation, and oligoclonal expansion, which are in keeping with their ability to function as active ectopic germinal centers (GCs), which can also support the production of autoreactive plasma cells at the local site of inflammation.

The biological events that bring to ELS formation in disease tissues show numerous similarities with the signaling pathways involved in secondary lymphoid tissue organogenesis; nevertheless, 
there are site-specific differences, particularly regarding the cellular sources of the key factors regulating lymphoid neogenesis, which depend, at least in part, on the nature of the site of inflammation $(1,2)$.

In this review, we shall first focus on the mechanisms regulating ELS formation and functions, including the well-established role of lymphoid chemokines and lymphotoxins (LTs) in ELS formation, together with the emerging importance of cytokines as positive (i.e., IL-21, IL-22) and negative (i.e., IL-27) regulators in ELS development, maintenance, and function. In the second part of this review, we shall discuss the evidence supporting the concept that ELS in autoimmune diseases contribute to the perpetuation and spreading of autoimmunity via the differentiation autoantibody-producing cells selected for disease-specific antigens within ectopic GCs. We will mostly focus on rheumatic autoimmune diseases, such as rheumatoid arthritis (RA) and Sjögren's syndrome (SS), but we will also refer to other organspecific autoimmune conditions to highlight differences in the antigen-driven process underlying ELS formation.

\section{DEVELOPMENT AND ORGANIZATION OF ELS: THE ROLE OF LYMPHOTOXINS AND LYMPHOID CHEMOKINES}

The signals regulating ELS formation and perpetuation, mostly referred as lymphoid neogenesis, largely overlap with those regulating the same events in SLOs during embryonic life, known as lymphoid organogenesis, but with notable differences in the cellular sources of these factors in ELS development (5). Either in SLOs and ELS formation and perpetuation, the chemoattractant signaling pathway involves several homeostatic lymphoid chemokines, such as CXCL13, CCL19, CCL21, and CXCL12, and their specific receptors CXCR5 (for CXCL13), CCR7 (for CCL19 and CCL21), and CXCR4 (for CXCL12). In classic models of lymphoid organogenesis, the interaction between hematopoietic lymphoid tissue inducer cells $\left(\mathrm{CD}^{-} \mathrm{CD} 4^{+} \mathrm{IL}-7 \mathrm{Ra}^{+} \mathrm{RANK}^{+}\right)$and VCAM-1 + ICAM-1 + $\mathrm{LTBR}^{+}$mesenchymal organizer cells drives the establishment of a LT $\alpha 1 \beta 2$ (also known as LT $\beta$ )/ lymphoid chemokine feedback loop, which is required for SLOs development including early $\mathrm{B} / \mathrm{T}$ cell clustering and segregation as well as the differentiation of HEVs, as reviewed extensively elsewhere $(1,6,7)$. Conversely, the early stages of lymphoid neogenesis in adult life are not fully understood, although recent evidence suggests an important role for inflammatory cytokines, such as IL-22 and IL-17, as early contributors in ELS formation, as discussed later. Regardless, once ELS are established, additional and/or alternative cell types can express lymphoid chemokines and LTs during chronic inflammation in autoimmune conditions. In ELS, myofibroblast-like stromal cells support the production of CCL21 around HEVs in the T cell-rich area of the lymphoid aggregate, whereas CXCL13 can be produced by infiltrating cells (i.e. CD $14^{+}$inflammatory monocytes, $\mathrm{CD}^{+} 8^{+}$macrophages, and memory $\mathrm{CD}^{+}{ }^{+} \mathrm{CD} 4^{+} \mathrm{T}$ cells) but also resident tissue cells such as activated stromal and epithelial cells (6). Therefore, it is believed that the immune cells recruited at the site of inflammation, in cross-talk with resident cells which are tissue-specific, exert an active role in the initiation of ELS development (2). Another example of the importance of the site-specific inflammatory milieu in ELS development and/or maintenance in autoimmune diseases is represented by TNF- $\alpha$, which is abundantly expressed in the synovium of RA patients. In this regard, evidence that TNF-blockade can reverse ELS formation in the joints, at least in a subset of patients, would suggest that in some conditions, TNF- $\alpha$ can play a non-redundant role in ELS maintenance over and above LT- $\beta$ (8).

Once ELS are established, lymphoid chemokines CCL19, CCL21, and CXCL13 are critical for their perpetuation and function by controlling the homing and tissue localization of immune cells subsets, which are crucial in adaptive immune responses. The concomitant presence of CCL19/CCL21 and peripheral node addressin (PNAd-positive) HEVs allows the homing of CCR7 ${ }^{+}$ $\mathrm{T}$ cells (i.e., naïve and central memory) and mature CCR7 ${ }^{+}$ dendritic cells (DCs) from the systemic circulation upon binding to PNAd ${ }^{+}$HEVs through L-selectin $(6,9)$. Naïve B cells can also express at lower level CCR7, and together with CXCR4 and CXCR5, they use these receptors to enter ELS from the systemic circulation $(6,10)$, although $\mathrm{B}$ cell positioning into ectopic follicles is mainly controlled by CXCR5 in response to a CXCL13 gradient. B cells can actively contribute to ELS maintenance as they become strong producers of LT $\beta$.

Lymphoid chemokines CXCL13 and CXCL12 are also critical in the function of ELS as ectopic GCs by regulating the shuttling of B cells between the dark and light zones. Inside the GC, CXCL13, mostly produced by FDCs, mainly directs GC B cells to the light zone of the GC where antigen selection occurs. Within the GC, CXCL12, mostly produced by tingible body macrophages in ELS (11), is critically involved in the migration of CXCR $4^{\text {high }}$ centroblasts to the dark zone, where somatic hypermutation of the $\mathrm{B}$ cell receptor takes place (6). As discussed later in this review, in the target organs of autoimmune diseases, the formation of functional GCs as a result of the lymphoid neogenesis process is critical in the selection and differentiation of autoantibodyproducing B cells.

\section{THE EMERGING ROLE OF CYTOKINES AS POSITIVE AND NEGATIVE REGULATORS OF ELS FORMATION, PERPETUATION, AND FUNCTION}

As mentioned earlier, besides the classic LT/lymphoid chemokines feedback loop, there is strong emerging evidence that cytokines produced in the context of the inflammatory process are also critically involved in the lymphoid neogenesis in autoimmune diseases. These include, not exhaustively, IL-17, IL-21, IL-22, IL-23, and TNF (2). For instance, IL-17 produced by a subset of podoplanin-expressing $\mathrm{CD} 4 \mathrm{~T}$ cells has been strongly linked with ELS formation in animal models of inducible ELS, and the IL-23/ IL-17 axis has been recently associated with ELS formation in RA $(12,13)$. Because the role of IL-17 in ELS has been recently reviewed extensively $(1,2)$, here we will focus on the emerging role of positive and negative regulators of ELS formation and function such as IL-21/IL-22 and IL-27, respectively. 
Using a model of inducible ELS formation, autoimmunity and exocrine dysfunction resembling SS that we recently developed and which is triggered by local viral infection in the salivary glands of C57BL/6 mice (3), Barone et al. demonstrated that the early production (i.e., within few hours from viral infection) of IL-22, a cytokine belonging to the IL-10 family, by $\gamma \delta \mathrm{T}$-cells first and by conventional CD4 T cells thereafter, was directly responsible for the induction of CXCL13 by a subset of resident stromal cells expressing gp38. Although IL-22 was able to induce CXCL13 in vitro in a LT- $\beta$-independent manner, it is yet to be established whether IL-22 is sufficient to induce ELS in vivo in the absence of lymphotoxins (12). These findings seem applicable to ELS forming in human autoimmune diseases, as IL-22 has been associated with the formation of inflammatory aggregates both in RA and SS $(13,14)$.

While IL-22 appears critical in the early phase of ELS development, another cytokine, IL-21, a member of the common cytokine receptor $\gamma$ chain-binding family, has been shown to play a fundamental role in the function of ELS as ectopic GCs. This cytokine is primarily produced by $\mathrm{T}$ follicular helper (Tfh) cells, a highly specialized subset of CD $4^{+}$memory T cells expressing high amount of CXCR5 (15) and thus able to migrate toward B cell follicles in response to CXCL13 production by FDCs.

In the last decade, Tfh cells have emerged as essential players in the regulation of $\mathrm{B}$ cell activation, antibody affinity maturation, and the GC reaction via the expression of surface receptors such as inducible T-cell costimulator (ICOS) and programed cell death protein 1 (PD1). They also express the transcription factor B cell lymphoma protein 6 (Bcl-6), which promotes the expression of CXCR5 and represses other T-cell subset-specific transcription factors (16-18). IL-21 is the main soluble factor released by $\mathrm{Tfh}$ and binds a receptor complex consisting of the common $\gamma$ chain and a unique IL-21R. On B cells, IL-21/ IL-21R interactions provide potent signaling for B-cell survival, proliferation, and differentiation (19). Indeed, the absence of Tfh cells impairs GC formation and the generation of longlived plasma cells, resulting in impaired high affinity antibody responses (20).

Among autoimmune diseases, elevated frequencies of Tfh cells in the peripheral blood have been demonstrated in RA, SS, multiple sclerosis (MS), myasthenia gravis (MG), and systemic lupus erythematosus (SLE) (21). Not surprisingly, IL-21 directly correlated with the frequency of Tfh-like cells. Both IL-21 level and number of Tfh-like cells were associated with higher titer of anti-CCP antibodies and disease activity score in RA (22). In the context of ELS, IL-21 and IL-21R expression are upregulated in the synovial tissue of RA patients, whereby IL-21 strictly segregates with the formation of ELS (23-25). Moreover, blocking IL-21/ IL-21R in animal models of RA and SS has a beneficial effect on the disease progression $(26,27)$.

Interestingly, plasticity between Th17 cells (but also Th1 and Th2) with Tfh cells has been observed (28) and may play an important role in autoimmune diseases, including models of experimental MS, whereby Th17 cells crossing the blood-brain barrier can acquire a Tfh-like cells phenotype, thus supporting ELS development and function in the central nervous system $(2,4)$. However, and of likely relevance to ELS and ectopic GC,
Tfh2 and Tfh17, but not Tfh1, are able to secrete IL-21 and induce naïve B cells to secrete class-switched immunoglobulin (Ig) (28).

Together with positive regulators of ELS formation, the existence of cytokines exerting a negative role on lymphoid neogenesis, such as IL-27, has been recently described. IL-27 is a heterodimeric cytokine belonging to the IL-12 family and is composed of EBI3 and IL-27p28 (29). IL-27 signals through a receptor were composed of IL-27R $\alpha$ and gp130, the latter used also by other cytokines such as IL-6 (29). IL-27 seems to be able to limit antibody production since overexpression of IL-27R $\alpha$ in the MLR/lpr mouse model of lupus can ameliorate the antibody response (29). Moreover, it has been recently shown that IL27 $\mathrm{R}^{-/-}$mice developed a more severe form of arthritis after immunization with methylated bovine serum albumin (mBSA), which was also characterized by multiple lymphoid aggregates forming in the inflamed synovial tissue (25). IL-27 can also restrict the expansion of Th17 cells and suppress secretion of IL-17, a cytokine associated also with survival and proliferation of B cells $(25,29,30)$. In regard to ELS development, e.g., in human synovium, it has been observed that IL-27 is inversely correlated with the degree of lymphocytic infiltration in the inflamed tissue as well as with the expression of IL-17 and IL-21 at mRNA level (25). However, further experimental and mechanistic data will be required before exploiting the role of IL-27 as a negative regulator of ELS formation and function for therapeutic purposes in autoimmune diseases.

\section{THE ROLE OF ELS AS PERPETUATORS OF AUTOIMMUNITY IN THE TARGET ORGANS OF AUTOIMMUNE DISEASES}

Ectopic lymphoid structures arise in the target organs of patients affected by autoimmune diseases, such as salivary glands in SS (6), synovial tissue in RA (31), kidneys in SLE (32), thymuses in MG (33), meninges in MS (34), and thyroids in Hashimoto's thyroiditis (35) (Figure 1A). However, for reasons that are currently not clear, the frequency of ELS in these conditions varies significantly, from a minority of patients with SLE to virtually $100 \%$ of patients with thyroiditis (36). For instance, in the RA synovium, the immune infiltrates can be arranged into three main microstructural levels of organization including (i) follicular synovitis with ELS (lymphoid pathotype, $40 \%$ of RA patients) $(31,37,38)$; (ii) diffuse pattern of infiltration with a predominant macrophages component (myeloid pathotype); and (iii) pauciimmune synovitis, characterized by a virtual absence of immune cells (fibroid pathotype) (39). Similarly, around $30-40 \%$ of patients with SS show ELS in the affected salivary glands $(40,41)$, and patients with ELS are significantly more likely to develop B-cell lymphomas of the mucosal-associated lymphoid tissue (MALT-L) $(42,43)$. In lupus nephritis, B/T cells aggregates can be found in up to $50 \%$ of patients in the tubulo-interstitium, but fully organized ectopic GC follicles are detectable in $<10 \%$ of patients (44). As previously mentioned, ELS in autoimmune conditions are not only structurally reminiscent of SLOs but also functionally active as ectopic GC. There is now conclusive evidence that ELS in autoimmune diseases favor the affinity maturation of B-cells via 


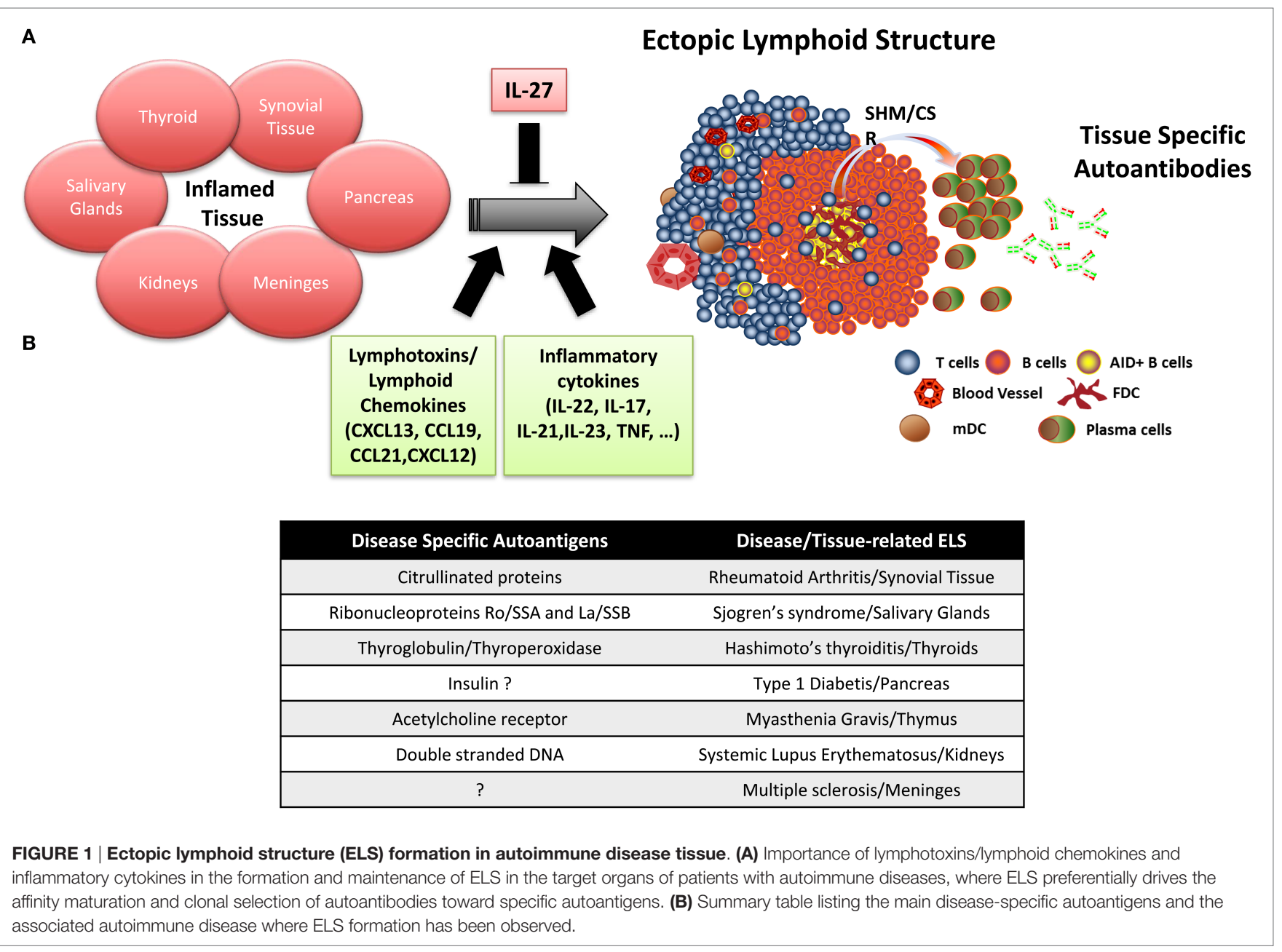

an antigen-driven selection process and their differentiation to plasma cells. B cell isolated from ELS in autoimmune conditions display highly somatically hypermutated Ig VH and VL regions in line with a local antigen-driven process (45-47). Furthermore, lineage tree analysis of the Ig gene repertoire of B-cells and plasma cells infiltrating ELS + tissues in autoimmune diseases proved that clonal diversification and differentiation to antibodyproducing cells take place within ELS $(45,47,48)$. In keeping with the above evidence, B cells within ELS display detectable activation-induced cytidine deaminase (49), the enzyme which regulates both somatic hypermutation and isotype class switching of the Ig genes (50).

Accumulating experimental data indicate that ELS in autoimmune diseases preferentially favor affinity maturation and clonal selection toward autoantigens, which are frequently the target of autoantibodies detectable in the patients' circulation (Figure 1B). Specifically, ELS allow the selection and differentiation of autoreactive $B$ cells into high-affinity plasma cells reacting against citrullinated antigens in RA (49), anti-ribonucleoproteins Ro/ SSA and La/SSB in SS (40), thyroglobulin and thyroperoxidase in Hashimoto's thyroiditis (35), and insulin in type 1 diabetes
$(51,52)$. More in details, we and other provided evidence that (i) perifollicular $\mathrm{CD} 138^{+}$plasma cells frequently bind biotinylated citrullinated fibrinogen and the Ro52 antigen in synovial and salivary gland ELS of RA and SS patients, respectively, but not vice versa, using double immunofluorescence experiments (40, 49, 53, 54); (ii) the engraftment of ELS + tissue from the RA synovium, SS salivary gland, and MG thymus in SCID mice in a series of chimeric human/murine models resulted in the release and detection of human autoantibodies against disease-specific autoantigens in the mouse circulation (54-56). More recently, (iii) by combining single B-cell sorting, Ig VH and VL gene cloning, and recombinant monoclonal antibody production from ELS + RA synovia or from ACPA + RA synovial fluid, we and others demonstrated that around $30 \%$ of the synovial humoral response is directed toward citrullinated antigens $(36,48)$.

Thus, in conclusion, although the processes underlying ELS formation in autoimmune diseases largely follow a stereotyped lymphoid neogenesis process, the autoantigens driving the autoimmune response within ELS in the respective target organs appear to be disease specific. An important consequence of this phenomenon is that a better understanding of the fine specificity 
of the autoantigens driving the autoimmune response within ELS would strongly enhance our knowledge of the underlying processes perpetuating autoimmunity and chronic inflammation in the different autoimmune diseases. Furthermore, and perhaps more importantly, the identification of dominant autoantigens driving $\mathrm{B}$ and $\mathrm{T}$ cell responses, as recently suggested by large throughput sequencing studies in the RA synovium, could pave the way for future vaccination and tolerogenic therapeutic strategies $(57,58)$.

\section{REFERENCES}

1. Pitzalis C, Jones GW, Bombardieri M, Jones SA. Ectopic lymphoid-like structures in infection, cancer and autoimmunity. Nat Rev Immunol (2014) 14:447-62. doi:10.1038/nri3700

2. Jones GW, Jones SA. Ectopic lymphoid follicles: inducible centres for generating antigen-specific immune responses within tissues. Immunology (2016) 147:141-51. doi:10.1111/imm.12554

3. Bombardieri M, Barone F, Lucchesi D, Nayar S, Van Den Berg WB, Proctor G, et al. Inducible tertiary lymphoid structures, autoimmunity, and exocrine dysfunction in a novel model of salivary gland inflammation in C57BL/6 mice. J Immunol (2012) 189:3767-76. doi:10.4049/jimmunol.1201216

4. Peters A, Pitcher LA, Sullivan JM, Mitsdoerffer M, Acton SE, Franz B, et al. Th17 cells induce ectopic lymphoid follicles in central nervous system tissue inflammation. Immunity (2011) 35:986-96. doi:10.1016/j.immuni.2011.10.015

5. Germain C, Gnjatic S, Dieu-Nosjean MC. Tertiary lymphoid structure-associated B cells are key players in anti-tumor immunity. Front Immunol (2015) 6:67. doi:10.3389/fimmu.2015.00067

6. Corsiero E, Bombardieri M, Manzo A, Bugatti S, Uguccioni M, Pitzalis C. Role of lymphoid chemokines in the development of functional ectopic lymphoid structures in rheumatic autoimmune diseases. Immunol Lett (2012) 145:62-7. doi:10.1016/j.imlet.2012.04.013

7. Randall TD, Mebius RE. The development and function of mucosal lymphoid tissues: a balancing act with micro-organisms. Mucosal Immunol (2014) 7:455-66. doi:10.1038/mi.2014.11

8. Canete JD, Celis R, Moll C, Izquierdo E, Marsal S, Sanmarti R, et al. Clinical significance of synovial lymphoid neogenesis and its reversal after anti-tumour necrosis factor alpha therapy in rheumatoid arthritis. Ann Rheum Dis (2009) 68:751-6. doi:10.1136/ard.2008.089284

9. Link A, Vogt TK, Favre S, Britschgi MR, Acha-Orbea H, Hinz B, et al. Fibroblastic reticular cells in lymph nodes regulate the homeostasis of naive T cells. Nat Immunol (2007) 8:1255-65. doi:10.1038/ni1513

10. Pereira JP, Kelly LM, Cyster JG. Finding the right niche: B-cell migration in the early phases of T-dependent antibody responses. Int Immunol (2010) 22:413-9. doi:10.1093/intimm/dxq047

11. Barone F, Bombardieri M, Rosado MM, Morgan PR, Challacombe SJ, De Vita S, et al. CXCL13, CCL21, and CXCL12 expression in salivary glands of patients with Sjogren's syndrome and MALT lymphoma: association with reactive and malignant areas of lymphoid organization. J Immunol (2008) 180:5130-40. doi:10.4049/jimmunol.180.7.5130

12. Barone F, Nayar S, Campos J, Cloake T, Withers DR, Toellner KM, et al. IL-22 regulates lymphoid chemokine production and assembly of tertiary lymphoid organs. Proc Natl Acad Sci U S A (2015) 112:11024-9. doi:10.1073/ pnas.1503315112

13. Canete JD, Celis R, Yeremenko N, Sanmarti R, Van Duivenvoorde L, Ramirez J, et al. Ectopic lymphoid neogenesis is strongly associated with activation of the IL-23 pathway in rheumatoid synovitis. Arthritis Res Ther (2015) 17:173. doi:10.1186/s13075-015-0688-0

14. Ciccia F, Guggino G, Rizzo A, Ferrante A, Raimondo S, Giardina A, et al. Potential involvement of IL-22 and IL-22-producing cells in the inflamed salivary glands of patients with Sjogren's syndrome. Ann Rheum Dis (2012) 71:295-301. doi:10.1136/ard.2011.154013

15. Breitfeld D, Ohl L, Kremmer E, Ellwart J, Sallusto F, Lipp M, et al. Follicular B helper T cells express CXC chemokine receptor 5, localize to B cell follicles,

\section{AUTHOR CONTRIBUTIONS}

All authors listed have made substantial, direct, and intellectual contribution to the work and approved it for publication.

\section{FUNDING}

This work was funded by research grants from Arthritis Research UK (grant 20089 to MB and grant 20858 to EC).

and support immunoglobulin production. J Exp Med (2000) 192:1545-52. doi:10.1084/jem.192.11.1545

16. Zotos D, Coquet JM, Zhang Y, Light A, D'Costa K, Kallies A, et al. IL-21 regulates germinal center $\mathrm{B}$ cell differentiation and proliferation through a B cell-intrinsic mechanism. J Exp Med (2010) 207:365-78. doi:10.1084/ jem.20091777

17. Shulman Z, Gitlin AD, Weinstein JS, Lainez B, Esplugues E, Flavell RA, et al. Dynamic signaling by $\mathrm{T}$ follicular helper cells during germinal center B cell selection. Science (2014) 345:1058-62. doi:10.1126/science.1257861

18. Liu D, Xu H, Shih C, Wan Z, Ma X, Ma W, et al. T-B-cell entanglement and ICOSL-driven feed-forward regulation of germinal centre reaction. Nature (2015) 517:214-8. doi:10.1038/nature13803

19. Karnell JL, Ettinger R. The interplay of IL-21 and BAFF in the formation and maintenance of human B cell memory. Front Immunol (2012) 3:2. doi:10.3389/ fimmu.2012.00002

20. Ballesteros-Tato A, Randall TD. Priming of T follicular helper cells by dendritic cells. Immunol Cell Biol (2014) 92:22-7. doi:10.1038/icb.2013.62

21. Ueno H, Banchereau J, Vinuesa CG. Pathophysiology of T follicular helper cells in humans and mice. Nat Immunol (2015) 16:142-52. doi:10.1038/ni.3054

22. Ma J, Zhu C, Ma B, Tian J, Baidoo SE, Mao C, et al. Increased frequency of circulating follicular helper T cells in patients with rheumatoid arthritis. Clin Dev Immunol (2012) 2012:827480. doi:10.1155/2012/827480

23. Jungel A, Distler JH, Kurowska-Stolarska M, Seemayer CA, Seibl R, Forster A, et al. Expression of interleukin-21 receptor, but not interleukin-21, in synovial fibroblasts and synovial macrophages of patients with rheumatoid arthritis. Arthritis Rheum (2004) 50:1468-76. doi:10.1002/art.20218

24. Kwok SK, Cho ML, Park MK, Oh HJ, Park JS, Her YM, et al. Interleukin-21 promotes osteoclastogenesis in humans with rheumatoid arthritis and in mice with collagen-induced arthritis. Arthritis Rheum (2012) 64:740-51. doi:10.1002/art.33390

25. Jones GW, Bombardieri M, Greenhill CJ, Mcleod L, Nerviani A, Rocher-Ros $\mathrm{V}$, et al. Interleukin-27 inhibits ectopic lymphoid-like structure development in early inflammatory arthritis. J Exp Med (2015) 212:1793-802. doi:10.1084/ jem.20132307

26. Young DA, Hegen M, Ma HL, Whitters MJ, Albert LM, Lowe L, et al. Blockade of the interleukin-21/interleukin-21 receptor pathway ameliorates disease in animal models of rheumatoid arthritis. Arthritis Rheum (2007) 56:1152-63. doi:10.1002/art.22452

27. Liu H, Liu G, Gong L, Zhang Y, Jiang G. Local suppression of IL-21 in submandibular glands retards the development of Sjogren's syndrome in non-obese diabetic mice. JOral Pathol Med (2012) 41:728-35. doi:10.1111/j.1600-0714.2012.01175.x

28. Morita R, Schmitt N, Bentebibel SE, Ranganathan R, Bourdery L, Zurawski G, et al. Human blood CXCR5(+)CD4(+) T cells are counterparts of T follicular cells and contain specific subsets that differentially support antibody secretion. Immunity (2011) 34:108-21. doi:10.1016/j.immuni.2010.12.012

29. Yoshida H, Hunter CA. The immunobiology of interleukin-27. Annu Rev Immunol (2015) 33:417-43. doi:10.1146/annurev-immunol-032414-112134

30. Stumhofer JS, Laurence A, Wilson EH, Huang E, Tato CM, Johnson LM, et al. Interleukin 27 negatively regulates the development of interleukin 17-producing $\mathrm{T}$ helper cells during chronic inflammation of the central nervous system. Nat Immunol (2006) 7:937-45. doi:10.1038/ni1376

31. Manzo A, Bombardieri M, Humby F, Pitzalis C. Secondary and ectopic lymphoid tissue responses in rheumatoid arthritis: from inflammation 
to autoimmunity and tissue damage/remodeling. Immunol Rev (2010) 233:267-85. doi:10.1111/j.0105-2896.2009.00861.x

32. Bird AK, Meednu N, Anolik JH. New insights into B cell biology in systemic lupus erythematosus and Sjogren's syndrome. Curr Opin Rheumatol (2015) 27:461-7. doi:10.1097/BOR.0000000000000201

33. Berrih-Aknin S, Ragheb S, Le Panse R, Lisak RP. Ectopic germinal centers, BAFF and anti-B-cell therapy in myasthenia gravis. Autoimmun Rev (2013) 12:885-93. doi:10.1016/j.autrev.2013.03.011

34. Magliozzi R, Howell O, Vora A, Serafini B, Nicholas R, Puopolo M, et al. Meningeal B-cell follicles in secondary progressive multiple sclerosis associate with early onset of disease and severe cortical pathology. Brain (2007) 130:1089-104. doi:10.1093/brain/awm038

35. Armengol MP, Juan M, Lucas-Martin A, Fernandez-Figueras MT, Jaraquemada D, Gallart T, et al. Thyroid autoimmune disease: demonstration of thyroid antigen-specific B cells and recombination-activating gene expression in chemokine-containing active intrathyroidal germinal centers. Am J Pathol (2001) 159:861-73. doi:10.1016/S0002-9440(10)61762-2

36. Aloisi F, Pujol-Borrell R. Lymphoid neogenesis in chronic inflammatory diseases. Nat Rev Immunol (2006) 6:205-17. doi:10.1038/nri1786

37. Takemura S, Braun A, Crowson C, Kurtin PJ, Cofield RH, O’Fallon WM, et al. Lymphoid neogenesis in rheumatoid synovitis. JImmunol (2001) 167:1072-80. doi:10.4049/jimmunol.167.2.1072

38. Dennis G Jr, Holweg CT, Kummerfeld SK, Choy DF, Setiadi AF, Hackney JA, et al. Synovial phenotypes in rheumatoid arthritis correlate with response to biologic therapeutics. Arthritis Res Ther (2014) 16:R90. doi:10.1186/ ar4555

39. Pitzalis C, Kelly S, Humby F. New learnings on the pathophysiology of RA from synovial biopsies. Curr Opin Rheumatol (2013) 25:334-44. doi:10.1097/ BOR.0b013e32835fd8eb

40. Salomonsson S, Jonsson MV, Skarstein K, Brokstad KA, Hjelmstrom P, Wahren-Herlenius $\mathrm{M}$, et al. Cellular basis of ectopic germinal center formation and autoantibody production in the target organ of patients with Sjogren's syndrome. Arthritis Rheum (2003) 48:3187-201. doi:10.1002/art.11311

41. Barone F, Bombardieri M, Manzo A, Blades MC, Morgan PR, Challacombe SJ, et al. Association of CXCL13 and CCL21 expression with the progressive organization of lymphoid-like structures in Sjogren's syndrome. Arthritis Rheum (2005) 52:1773-84. doi:10.1002/art.21062

42. Bombardieri M, Barone F, Humby F, Kelly S, Mcgurk M, Morgan P, et al. Activation-induced cytidine deaminase expression in follicular dendritic cell networks and interfollicular large B cells supports functionality of ectopic lymphoid neogenesis in autoimmune sialoadenitis and MALT lymphoma in Sjogren's syndrome. J Immunol (2007) 179:4929-38. doi:10.4049/ jimmunol.179.7.4929

43. Theander E, Vasaitis L, Baecklund E, Nordmark G, Warfvinge G, Liedholm R, et al. Lymphoid organisation in labial salivary gland biopsies is a possible predictor for the development of malignant lymphoma in primary Sjogren's syndrome. Ann Rheum Dis (2011) 70:1363-8. doi:10.1136/ard.2010. 144782

44. Chang A, Henderson SG, Brandt D, Liu N, Guttikonda R, Hsieh C, et al. In situ $\mathrm{B}$ cell-mediated immune responses and tubulointerstitial inflammation in human lupus nephritis. J Immunol (2011) 186:1849-60. doi:10.4049/ jimmunol.1001983

45. Stott DI, Hiepe F, Hummel M, Steinhauser G, Berek C. Antigen-driven clonal proliferation of B cells within the target tissue of an autoimmune disease. The salivary glands of patients with Sjogren's syndrome. J Clin Invest (1998) 102:938-46. doi:10.1172/JCI3234

46. Cheng J, Torkamani A, Grover RK, Jones TM, Ruiz DI, Schork NJ, et al. Ectopic B-cell clusters that infiltrate transplanted human kidneys are clonal. Proc Natl Acad Sci U S A (2011) 108:5560-5. doi:10.1073/pnas.1101148108
47. Scheel T, Gursche A, Zacher J, Haupl T, Berek C. V-region gene analysis of locally defined synovial B and plasma cells reveals selected B cell expansion and accumulation of plasma cell clones in rheumatoid arthritis. Arthritis Rheum (2011) 63:63-72. doi:10.1002/art.27767

48. Corsiero E, Bombardieri M, Carlotti E, Pratesi F, Robinson W, Migliorini P, et al. Single cell cloning and recombinant monoclonal antibodies generation from RA synovial B cells reveal frequent targeting of citrullinated histones of NETs. Ann Rheum Dis (2016) 75(10):1866-75. doi:10.1136/ annrheumdis-2015-208356

49. Humby F, Bombardieri M, Manzo A, Kelly S, Blades MC, Kirkham B, et al. Ectopic lymphoid structures support ongoing production of class-switched autoantibodies in rheumatoid synovium. PLoS Med (2009) 6:e1. doi:10.1371/ journal.pmed.0060001

50. Muramatsu M, Kinoshita K, Fagarasan S, Yamada S, Shinkai Y, Honjo T. Class switch recombination and hypermutation require activation-induced cytidine deaminase (AID), a potential RNA editing enzyme. Cell (2000) 102:553-63. doi:10.1016/S0092-8674(00)00078-7

51. Kendall PL, Yu G, Woodward EJ, Thomas JW. Tertiary lymphoid structures in the pancreas promote selection of B lymphocytes in autoimmune diabetes. J Immunol (2007) 178:5643-51. doi:10.4049/jimmunol.178.9.5643

52. Astorri E, Bombardieri M, Gabba S, Peakman M, Pozzilli P, Pitzalis C. Evolution of ectopic lymphoid neogenesis and in situ autoantibody production in autoimmune nonobese diabetic mice: cellular and molecular characterization of tertiary lymphoid structures in pancreatic islets. J Immunol (2010) 185:3359-68. doi:10.4049/jimmunol.1001836

53. Rangel-Moreno J, Hartson L, Navarro C, Gaxiola M, Selman M, Randall TD. Inducible bronchus-associated lymphoid tissue (iBALT) in patients with pulmonary complications of rheumatoid arthritis. JClin Invest (2006) 116:3183-94. doi:10.1172/JCI28756

54. Croia C, Astorri E, Murray-Brown W, Willis A, Brokstad KA, Sutcliffe N, et al. Implication of Epstein-Barr virus infection in disease-specific autoreactive $B$ cell activation in ectopic lymphoid structures of Sjogren's syndrome. Arthritis Rheumatol (2014) 66:2545-57. doi:10.1002/art.38726

55. Yoshikawa H, Lennon VA. ACh receptor protein drives primary and memory autoantibody responses in chimeric human-SCID mice. Clin Immunol (2002) 104:128-37. doi:10.1006/clim.2002.5251

56. Croia C, Serafini B, Bombardieri M, Kelly S, Humby F, Severa M, et al. Epstein-Barr virus persistence and infection of autoreactive plasma cells in synovial lymphoid structures in rheumatoid arthritis. Ann Rheum Dis (2013) 72:1559-68. doi:10.1136/annrheumdis-2012-202352

57. Klarenbeek PL, De Hair MJ, Doorenspleet ME, Van Schaik BD, Esveldt RE, Van De Sande MG, et al. Inflamed target tissue provides a specific niche for highly expanded T-cell clones in early human autoimmune disease. Ann Rheum Dis (2012) 71:1088-93. doi:10.1136/annrheumdis-2011-200612

58. Doorenspleet ME, Klarenbeek PL, De Hair MJ, Van Schaik BD, Esveldt RE, Van Kampen AH, et al. Rheumatoid arthritis synovial tissue harbours dominant B-cell and plasma-cell clones associated with autoreactivity. Ann Rheum Dis (2014) 73:756-62. doi:10.1136/annrheumdis-2012-202861

Conflict of Interest Statement: The authors declare that the research was conducted in the absence of any commercial or financial relationships that could be construed as a potential conflict of interest.

Copyright $\odot 2016$ Corsiero, Nerviani, Bombardieri and Pitzalis. This is an open-access article distributed under the terms of the Creative Commons Attribution License (CC BY). The use, distribution or reproduction in other forums is permitted, provided the original author(s) or licensor are credited and that the original publication in this journal is cited, in accordance with accepted academic practice. No use, distribution or reproduction is permitted which does not comply with these terms. 